Мария Семиколенных ${ }^{1}$

\title{
ЛЕОНАРДО БРУНИ И ГЕОРГИЙ ТРАПЕЗУНДСКИЙ О СТРАТЕГИЯХ ПЕРЕВОДА ДРЕВНЕГРЕЧЕСКИХ АВТОРОВ 2
}

\begin{abstract}
Аннотация. Статья посвящена одному из эпизодов полемики о теории и практике перевода, развернувшейся в эпоху раннего Ренессанса, а именно тому, как цели и методы перевода представлены в трактате Леонардо Бруни «О правильном переводе» и в сочинениях одного из самых талантливых и плодовитых переводчиков того времени Георгия Трапезундского. Хотя основные принципы, которыми руководствовались оба автора, были сформулированы ещё в Античности, их взгляды на средневековую практику буквального перевода существенно отличаются: если Бруни считал, что средневековые переводчики «коверкали и уродовали» произведения древних авторов, то Георгий считал их методы наиболее подходящими для перевода «научных» сочинений (таких, как трактаты Аристотеля и других философов). Ключевые слова: перевод, Георгий Трапезундский, Леонардо Бруни, Демосфен.
\end{abstract}

\section{Maria V. Semikolennykh}

\section{LEONARDO BRUNI AND GEORGE OF TREBIZOND ON THE TRANSLATION OF ANCIENT GREEK AUTHORS}

Abstract. The paper addresses one of the episodes in the history of the early Renaissance polemic about the theory and practice of translation, namely, the views on the goals and methods of translation as presented in Leonardo Bruni's treatise De interpretatione recta and in the writings of one of the most talented and prolific translators of the time, George of Trebizond. Although the basic principles of translation which guided both authors dated back to the Antiquity, their views on the medieval practice of literal translation are rather different: while Bruni believed that medieval translators "distorted and mutilated" the works of ancient authors, George considered their methods to be the most suitable for the translation of "scholarly" writings (such as treatises of Aristotle and other philosophers).

Keywords: translation, George of Trebizond, Leonardo Bruni, Demosthenes.

\section{1. Введение}

Начало эпохи Возрождения было отмечено падением одних государств и возникновением других, массовыми переселениями, военными и религиозными конфликтами, столкновениями разных народов и традиций. Неудивительно,

1 Семиколенных Мария Владимировна - кандидат культурологии, научный сотрудник Русской Христианской Гуманитарной Академии.

Maria V. Semikolennykh, PhD, Research Fellow, Russian Christian Academy for the Humanities. maria.semikolennykh@gmail.com

2 Исследование выполнено при финансовой поддержке РФФИ в рамках научного проекта № 18-011-00669 «Риторические стратегии в истории византийской литературы».

This paper is part of the research project no. 18-011-00669 supported by the Russian Foundation for Basic Research. 
что в этом новом мире, где наряду с народными языками и диалектами активно использовались латинский язык, древне- и среднегреческий, османский, персидский, арабский и многие другие языки, практические и теоретические проблемы перевода приобретают особую остроту и становятся предметом оживлённой дискуссии. В Западной Европе, в особенности в Италии, куда в первую очередь устремились после падения Константинополя византийские интеллектуалы, начало этой дискуссии оказалось естественным образом связано с активным переводом произведений древнегреческих писателей на латинский язык. Работа множества переводчиков, зачастую соперничавших между собой, подразумевала необходимость формулировки профессиональных стандартов, своего рода теории перевода, которую естественным образом возводили всё к тем же авторам древности, в первую очередь Цицерону. Однако интеллектуалы эпохи Возрождения не только усвоили цицероновский метод, кратко охарактеризованный в сочинении «О наилучшем роде ораторов», но и развивали и видоизменяли его, как того требовало решение встававших перед ними новых переводческих задач. Яркими примерами такого развития античных и средневековых подходов к переводу стали сочинения Леонардо Бруни и Георгия Трапезундского. Сходство и различие в их взглядах и методах наиболее очевидным образом проявилось в том, как два этих выдающихся гуманиста своего времени подошли к переводу речи Демосфена «За Ктесифонта о венке», считавшейся вершиной ораторского искусства а потому - самым сложным вызовом, который только мог встать перед переводчиком.

\section{2. Представления античных и средневековых авторов о переводе ${ }^{3}$}

Древние греки не придавали большого значения точности перевода и цитирования: всё усваиваемое от иноземцев растворялось в общем литературном «корпусе» и (пользуясь словами Платона) «доводилось до совершенства» (Платон 1999: 988а): становилось по сути дела греческим. Тот же подход к заимствованию иноязычной мудрости формулирует Цицерон, который в «Тускуланских беседах» пишет: «...наши римские соотечественники во всём как сами умели делать открытия не хуже греков, так и заимствованное от греков умели улучшить и совершенствовать» (Цицерон 1975: I, 1, 1). В предисловии к своему утраченному переводу речей Эсхина «Против Ктесифонта» и Демосфена «За Ктесифонта о венке» он отмечает: «Перевел я их, однако, не как толмач, а как оратор: я сохранил и мысли, и их построение их физиономию, так сказать - но в подборе слов руководился условиями нашего языка. При таком отношении к делу я не имел надобности переводить

3 Следующий раздел является пересмотренной и дополненной версией соответствующего раздела статьи Basilios Bessarion on George of Trebizond's translation of Plato's Laws (2019), в данный момент находящейся на рассмотрении в The European Journal of Humour Research. 
слово в слово, а только воспроизводил в общей совокупности смысл и силу отдельных слов» (Цицерон 1901: V, 14). Гораций в «Искусстве поэзии» (Гораций 1936: 133-135) советует придерживаться некоего «среднего пути», воздерживаясь как от буквального, так и от чересчур свободного перевода (nec verbo verbum curabis reddere fidus / interpres nec desilies imitator in artum). Во II веке Авл Гелий, рассуждая об удачных и неудачных переводах стихов Гомера, принадлежащих Вергилию, заметил: «...когда нужно переложить и воспроизвести замечательные выражения из греческих стихов, не всегда следует стремиться [к тому], чтобы перевести все слова совершенно так, как они сказаны. Ведь многие [стихи] теряют приятность, если их переводят словно бы против желания, и они сопротивляются насилию» (Авл Гелий 2007: 386). Таким образом, перевод оказывается не рабским подражанием оригиналу, а достаточно свободным творческим действием или даже литературным соревнованием (aemulatio), в котором переводчик пытается сравняться со избранным автором, если не вовсе его превзойти. Зияние между оригинальной и переводной литературой полностью отсутствует: с одной стороны, буквальный перевод не следует оригиналу, с другой - сам оригинал не так уж важен, важен актуальный текст (Flashar 1968: 137). Несколькими столетиями позднее Иероним, опираясь на суждения того же Цицерона, настаивал, что переводить следует «не слово словом, но мысль мыслью» (Иероним 2015: $319)$, ссылался на опыт множества именитых переводчиков, которые «не корпели над мертвой буквой, и не истязали себя нудным переводом, как невежды, но как бы по праву победителя переложили плененные мысли на свой язык» (Иероним 2015: 322). Цитируя предисловие к житию святого Антония, он отмечает, что «дословный перевод с одного языка на другой затемняет смысл, как разросшийся сорняк заглушает семя», и советует адресату: «Пусть другие гоняются за слогами и буквами, ты же ищи мыслей» (Иероним 2015: 321), - а также показывает, что от буквального перевода воздерживались «мужи Церкви, переводившие Септуагинту, и Евангелисты и Апостолы» (Иероним 2015: 322).

Тем не менее, в Средние века сформировалась и стала доминирующей традиция точного и буквального перевода. Такой подход мы можем заметить, например, у Боэция, который в предисловии к своему переводу Isagoge Порфирия опасается: «Как бы не впасть мне в грех чересчур добросовестного переводчика, передающего всё слово в слово и не решающегося отступить от буквы оригинала. Впрочем, и в таком подходе есть свой смысл: ведь для подобного рода научных сочинений не так важна изысканность пышного слога, как сохранение неискажённой истины» (Боэций 1990: 5). Отчасти же здесь прослеживается арабское влияние: на арабский в первую очередь были переведены медицинские трактаты греков, а затем - философские сочинения, без которых сложно было разобраться в представлениях древнегреческих медиков. Такого рода «научный» перевод требовал точности, стройно- 
сти, единообразия, - а поскольку, благодаря арабскому влиянию, в средневековую Европу приходили чаще всего именно научные сочинения греков, усвоен был и арабский подход к переводу (Flashar 1968: 141-143; Kelly 2009: 480-481). Правилом становится verbum de verbo reddere, причём не только при работе с языком-посредником, но и в случае прямого перевода с греческого. Отчасти это приводило к буквализму без понимания смысла, отчасти предполагало очень скрупулёзное отношение к оригиналу (таким переводчиком был, например, друг Фомы Аквинского Вильем из Мёрбеке, переводивший в XIII веке Прокла и Аристотеля непосредственно с греческого языка). Складывался метод решения конкретных переводческих задач, а переводы становились однородными в стилистическом отношении (Flashar 1968: 143). Одновременно с этим (в области, прежде всего, перевода поэтических сочинений различных жанров на народные языки) сохранялся и развивался метод перевода более свободного, связанный, тем не менее, со вполне схоластической практикой комментирования и экзегезы: в данном случае оригинальный текст не дополняется, а замещается своего экзегетическим парафразом на языке перевода (Copeland 1991: 175-177; Zaharia 2014: 13-14).

С началом эпохи Ренессанса обе эти традиции: буквального перевода и свободного парафраза или подражания, translatio и imitatio, - оказались востребованными, подверглись переосмыслению и существовали бок о бок, в непрерывном диалоге. Переводчикам приходилось или делать выбор в пользу одного из подходов, или пытаться их совмещать. При этом речь шла не только о теоретических проблемах перевода, но и вещах вполне земных: переводчику был необходим покровитель (Kelly 2009: 481-482) - правитель, богатый аристократ или прелат, способный профинансировать розыски старинных рукописей, существование библиотеки, работу самого переводчика и мастеров, создававших книги (писцов, переплётчиков, иллюстраторов, позднее печатников). Важно было завоевать и сохранить профессиональную репутацию, а для этого - продемонстрировать своё искусство и глубокое понимание принципов, которыми должен руководствоваться хороший переводчик. Таким образом, неизбежной стала широкая и бурная полемика о стратегиях перевода, в которую оказались вовлечены Леонардо Бруни и Георгий Трапезундский.

\section{2. Леонардо Бруни и трактат «О правильном переводе»}

Перу итальянского гуманиста, государственного деятеля, историка и писателя Леонардо Бруни (1369-1444), помимо латинских и итальянских жизнеописаний Цицерона, Аристотеля, Данте, Петрарки и Бокаччо, речей, писем, философских трактатов и «Истории флорентийского народа», принадлежит множество переводов древнегреческих авторов: от Гомера, Платона и Аристотеля до Аристофана, Плутарха и Василия Великого (Шабага 2010: 29). 
При жизни и около века после своей смерти Бруни (или «Аретинец», как его называли по месту рождения, Ареццо) был невероятно популярен по всей Европе: существуют тысячи манускриптов с его произведениями - это больше, чем у какого-либо иного писателя эпохи Ренессанса (Hankins 2014: 57). Среди этого обширного литературного наследия есть и едва ли не первое со времён письма Иеронима Паммахию сочинение, специально посвящённое проблемам перевода: «О правильном переводе» (De interpretatione recta). Оно было написано в 1424-1426 годах, когда Бруни столкнулся с критикой выполненного им ранее перевода «Никомаховой этики» Аристотеля (Linde 2018: 49): в предисловии к нему он резко высказался о «старом переводчике» (vetus interpres) (Вильеме из Мёрбеке, который по просьбе Фомы Аквинского перевёл это сочинение Аристотеля особенно близко к тексту (Hankins 2014: 57 n. 1 $)^{4}$ ), а теперь желал объяснить, что именно в этом переводе вызвало такое его негодование. По словам писателя, на греческом языке книги Аристотеля были «полными изящества, полными красоты, полными какой-то невыразимой прелести», а в переводе на латинский язык оказались «исковерканными и изуродованными» (Бруни 2010: 44). Правила, которые он формулирует, призваны были предотвратить появление плохих переводов.

Прежде всего, согласно Бруни, переводчик должен обладать «глубокими и совершенными знаниями» языка оригинала, приобретённым «разнообразным, изнурительным, вдумчивым, усердным и многолетним чтением произведений самых разных философов, ораторов, поэтов и других сочинителей» (Бруни 2010: 45). Кроме того, не менее глубоко ему следует знать язык, на который он собирается переводить, чтобы в «известной мере им повелевать и держать в полной своей власти, и когда потребуется заменить греческое слово латинским, не вымаливать его как подаяние, или одалживать, или же оставлять греческий термин без перевода из-за незнания его латинского эквивалента» (Бруни 2010: 48). Кроме того, переводчик должен «прекрасно знать общепринятую манеру изъясняться и фигуры речи, используемые первоклассными писателями, стиль которых он будет воспроизводить» (Бруни 2010: 48). В этом Бруни следует Цицерону, который требовал, чтобы переводчик был конгениальным своему автору оратором и отмечал, что «кто воспроизведет стиль Демосфена, будет заодно и самым аттическим и наилучшим оратором» (Цицерон 1901: IV.13). Кроме того, следовало избегать необычных слов и выражений, «особенно если они нетипичны для языка перевода или являются варваризмами», и обладать «тонким слухом» и вкусом, чтобы перевод звучал так же «изящно и ритмично», как и оригинал (Бруни 2010: 48). Таким образом, Леонардо Бруни считает важным передачу не только смысла рассуждений автора, но и его литературного стиля, всех особенностей оригинала: «...будет цениться только тот переводчик, кото-

4 Речь также могла идти о Роберте Гроссетесте (Linde 2018: 79). 
рый передаст оба этих достоинства» (Бруни 2010: 48). Отсюда и список недостатков перевода: переводчик поступает дурно, «если он плохо понимает то, что должен переводить; или делает плохой перевод; или если то, что в оригинале было написано хорошим и изящным слогом, он перелагает таким образом, что это становится нелепым, нескладным и бессвязным» (Бруни 2010: 49).

Отметим, что Бруни не делает никакого исключения для сочинений философов. Более того, всё сказанное им в особенности касается перевода сочинений Платона и Аристотеля (Бруни 2010: 48). Рассуждая о передаче в переводе ритмической речи авторов древности, он говорит, что «даже Демосфен или Цицерон, являющиеся мастерами слова и вообще ораторского искусства, не пользуются этими украшениями речи лучше, чем ими пользуется Аристотель», и что «сам я подчас не мог не изумляться тому, что философ, погружённый в глубочайшие научные проблемы, заботился и об этом» (Бруни 2010: 54).

В число почитателей Бруни-переводчика входил и Георгий Трапезундский. В письме своему ученику, Пьетро Гамбакорта, предпосланном составленному для того одному из первых «гуманистических» учебников логики, Isagoge Dialectica (1439-1440), Георгий не обходится без упрёка в адрес современных ему переводчиков, «варварски» (barbariem) обращающихся с сочинениями перипатетиков, однако хвалит переводы своего современника, Леонардо Бруни, «мужа, благодаря которому наш век смог бы соперничать слогом с древностью» ${ }^{5}$. Однако позднее, взявшись за перевод речи Демосфена «О венке», он уже критиковал Бруни за слишком вольное обращение с текстом.

\section{3. Георгий Трапезундский и его метод перевода}

Георгий Трапезундский родился 3 апреля 1395 года на Крите, приблизительно в 1416 году перебрался в Италию, учился латинскому языку у Витторино да Фельтре, а в 1427 году (возможно, даже раньше: первые упоминания о частных уроках относятся к 1422 году) уже преподавал в Венеции риторику, латинский и греческий языки, причём именно латинское красноречие было для него основным предметом интереса: преподавание риторики, литературные труды и переводы с греческого на латинский язык стали главным делом его жизни. Как писал он сам, уже через несколько лет занятий латинским он говорил на этом языке так хорошо, что мог одновременно диктовать двум проворным писцам речи на две разные темы. В 1433 или 1434 году он опубликовал свой opus magnum: Rhetoricorum Libri V, в которой впервые представил латинянам византийскую риторическую традицию. К этому же периоду

5 Georgius Trapezuntius, ÖBN, lat. 2485: f. 1v: "...vir quo aetas nostra in dicendo cum antiquitatem possit contendere". 
относится его, вероятно, наиболее популярное произведение: учебник грамматики De partibus orationis ex Prisciano compendium, широко использовавшийся в итальянских школах в XV веке. В 1439-1440 гг. он составил первый «гуманистический» учебник логики: Isagoge Dialectica. По-видимому, летом 1440 года Георгий стал секретарём папской курии, и к этому же времени относится начало его переводческой карьеры: в декабре 1440 года Виссарион Никейский заказал ему перевод трактата Василия Великого «Против Евномия». Первый опыт оказался успешным, и Виссарион рекомендовал Георгия папе Евгению IV как исключительно способного переводчика. Для Евгения IV и, в особенности, Николая V с его «переводческой фабрикой» (Flashar 1968: 144), Георгий перевёл множество произведений греческих авторов: за пять лет, которые он служил последнему (1447-1452), им были переведены одиннадцать текстов, по большей части весьма сложных и объёмных. В их число вошли «Альмагест» Птолемея, гомилии Иоанна Златоуста, «Евангельское приуготовление» Евсевия Кессарийского, сочинения Кирилла Александрийского, Василия Великого, Григория Нисского и Аристотеля. В период между апрелем 1450 и мартом 1451 года он перевёл и «Законы» Платона (Castellani 1896; Monfasani 1976; Viti 2001). Его талант и компетентность не ставились под сомнение: в частности, известно, что Поджио Браччолини обращался к нему за помощью в переводе «Киропедии» Ксенофонта и «Истории» Диодора Сицилийского.

Оказавшись, как и все современные ему переводчики, перед дилеммой: переводить буквально или подражать оригиналу, - Георгий выработал свой собственный метод, который неоднократно излагал в письмах и полемических сочинениях (Hankins 1990: 186-188; Monfasani 1976: 152-154; Monfasani 2006). Так, в сочинении Adversus Theodorum Gazam (1453/54) он упрекал соперника в том, что тот дурно перевёл Problemata Аристотеля, которые Георгий ранее сам перевёл для Николая V. Разбирая перевод соперника и указывая на допущенные тем ошибки, Георгий пояснял, в чём состоит задача добросовестного переводчика (fidus interpres): «То, что Аристотель написал ясно, он переводит ясно, то, что тот написал двусмысленно или темно, - соответствующим образом. Ведь так каждый будет всё по отдельности исследовать самостоятельно. Если же ты полагаешь, что некоторые тёмные места тебе понятны, или полагаешь, что двусмысленности для тебя разрешены, напиши на полях, - как мы имеем привычку делать, - что думаешь, и не смешивай свои слова со словами другого. Ведь так и Аристотель останется нетронутым, и мнение твое не канет в безвестность» ${ }^{6}$. Далее он перечисляет свои претензии к переводу Газы, слишком вольно (вплоть до перестановки

6 Mohler 1942: 298-299; Hankins 1990: 188: "Fidus interpres, quae Aristoteles dilucide scripsit, ea dilucide, quae ambigue aut obscure, ea similiter traducit. Sic enim pro ingenio quisque suo singular examinabit. Si vero nonnula obscura liquid tibi patere putas aut ambigua tibi certiora esse ducis, in marginibus, sicuti nos facere consuevimus, quae sentis, scribe nec tua non erit ignota". 
отдельных фрагментов и включения непосредственно в текст перевода собственных комментариев и примеров) обращавшегося с сочинением философа древности: «А ты что делаешь? Отнимаешь [у нас] Аристотеля. Многое словно бы от себя хулишь. Многое добавляешь. Многое изменяешь. А что не понимаешь - словно ошибки исправляешь. И такого немало» ${ }^{7}$

Таким образом, по крайней мере, для перевода сочинений Аристотеля Георгий Трапезундский считал необходимым придерживаться метода буквального перевода. Толкование сложностей и двусмысленностей следовало выносить за границы перевода - в схолии и комментарии. Сходным образом он высказывался и о Платоне: в письме к Николаю Кузанскому, который в 1458 году заказал ему перевод Парменида, Георгий отмечает, что Платон в этом диалоге так лаконичен, что более сжато передать ту же мысль нельзя, и что именно этого и требует предмет, о котором идёт речь, а затем добавляет, что, чем изящнее (ornatius) кто-нибудь пытается передать «сокрытые и тайные вещи», тем менее он способен их объяснить (Monfasani 1983: 303). Интересно, что, в противоположность Леонардо Бруни, порицавшему средневековых переводчиков (что в целом было для переводчиков-гуманистов общим местом), Георгий, споря с Феодором Газой, напротив, превозносил veteres interpretes, чьими трудами пользовались Альберт Великий и Фома Аквинский, и полагал, что может по праву встать в один ряд с ними (Mohler 1942: 319-321). Возможно, это было связано с его всё более углублявшимся с годами интересом к схоластике (Monfasani 2018); с другой стороны, как отмечает Дж. Корнелия Линде, дело могло быть и в разнице намерений: Георгий стремился дискредитировать соперника, и ссылка на авторитет могла быть риторическим приёмом (Linde 2018: 64-65).

Однако Георгий не считал, что буквальный перевод, снабжённый комментариями - единственный возможный метод. В том же сочинении против Газы он отмечает, что правила, которых должен придерживаться переводчик, определяются жанровой природой произведения (Mohler 1942: 278). В предисловиях к своим многочисленным переводам он указывал, что долг переводчика - как можно точнее воспроизводить оригинал, ибо только сам автор в состоянии должным образом выразить свои мысли. А, например, в предисловии к переводу «Физики» Аристотеля писал, что стремился быть не менее красноречивым и изысканным, чем сам философ (Monfasani 1976: 143). Особенно интересно в этом отношении предисловие к речи Демосфена «О венке», написанное в период между 1444 и 1446 годами для неизвестного адресата (Дж. Монфасани полагает, что этим анонимом мог быть учитель Георгия, Витторино да Фельтре, по всей видимости, одобривший его попытку

7 Mohler 1942: 299: "Nunc quid facis? Derogas Aristoteli. Multa desuis quasi maledicta tollis. Multa addis. Multa commutas. Et quae non intellegis, quasi mendosa sint, emendas. Quae non pauca sunt". Следует заметить, впоследствии, при переиздании перевода, Феодор Газа учёл критику Георгия (Monfasani 1976: 153 and n. 94). 
вступить в соперничество с Бруни (Monfasani 1983: 93-94)), а затем, в 1452 или 1453 году, переадресованное неаполитанскому патрону Георгия, Альфонсо V Великодушному.

\section{4. Предисловие Георгия Трапезундского к переводу речи Демосфена «За Ктесифонта о венке»}

Речь Демосфена «За Ктесифонта о венке» - прекрасная отправная точка для разговора о переводе хотя бы потому, что трактат Цицерона «О наилучшем роде ораторов» был предисловием именно к переводу этой речи (и предшествовавшей ей речи Эсхина). Известно, что Демосфен принимал участие в восстановлении стен родного города, за что другой афинский оратор, Ктесифонт, предложил увенчать его золотым венком за заслуги перед государством во время Дионисий, в театре Диониса. Соперник Демосфена Эсхин внёс жалобу против этой псефизмы на том основании, что Демосфен в тот момент занимал государственную должность и, следовательно, по закону не мог быть увенчан. Кроме того, он дурно отзывался о политической деятельности оратора, обвинял того во взяточничестве и в том, что его действия шли во вред Афинам. Ответная речь Демосфена на протяжении столетий считалась лучшей из его речей и непревзойдённым образцом ораторского искусства.

Леонардо Бруни перевёл эту речь в 1407 году (почти за двадцать лет до того, как написал De interpretatione recta), причём в предисловии к переводу ясно дал понять, что его первоочередной целью является подражание риторическому искусству Демосфена с целью доставить удовольствие читателю: практическая цель - отразить содержание речи и сделать его доступным для тех, кто не знал греческого языка, - имела второстепенное значение; более того, он не стал даже подчёркивать основную тему статьи, которая должна была быть близка сердцу его земляков-флорентийцев - защиту свободы (Davies 1988: 131). Он предположил, что читателей не заинтересуют тонкости афинского законодательства и военной истории, а потому обошёлся с текстом более чем свободно, сокращая, дополняя, разъясняя его и даже опуская довольно большие фрагменты - всё для того, чтобы получить речь, которую было бы приятно читать по-латыни (Ibid.). Далеко не все его современники были удовлетворены подобным подходом, и потому вскоре начали появляться другие переводы речи «О венке»: вскоре (во многом благодаря тому, что шире стал известен упомянутый выше трактат Цицерона), попытка перевода этого сочинения стала своего рода способом заявить о себе (Davies 1988: 132). Наряду с такими гуманистами, как Лоренцо Валла и Никколо Сагундино, в середине 1440-х годов в этом своеобразном соревновании принял участие и Георгий Трапезундский (Monfasani 1983: 93-97). 
Начинает Георгий с того, что заявляет, что все его предшественники были «полузнайками» (Grece lingue sciolis) и что он принялся за труд, ибо они, с одной стороны, опустили множество «постановлений и эдиктов» (decreta et litteras), а с другой - перевели речь так, что перевод совершенно непохож на оригинал. При переводе, - рассуждает он далее, - прежде всего следует позаботиться о том, чтобы отразить «род речи, великолепие композиции, разнообразие слога» (dicendi modus, compositionis splendor, orationis varietas), причём рода или «способы» речи (modus) бывают разными, и это определяет метод перевода. Тот, кто переводит сочинения «сложные, для понимания и разума трудные и большей частью даже у самих своих авторов двусмысленные» (qui ardua, sensu intellectuque difficilia, et plerumque vei apud ipsos auctores suos ambigua), должен переводить двусмыслицу двусмысленно, а точное - точно (ambigue ambigua, certiora certius). Как видно, это соответствует его мнению, позднее высказанному в критическом разборе перевода Газы.

Другие жанры, - продолжает Георгий, - требуют иного подхода. Переводя историческое сочинение, не следует заботиться о словах: в этом случае переводчику достаточно уяснить себе содержание речи и изложить его в своей собственной манере (more suo), сокращая и добавляя, что сочтёт нужным. Совершенно иным должен быть подход к переводу произведений греческих ораторов. В этом случае нельзя пренебрегать ни словами, ни смыслом речи: воспроизводить её следует со всей возможной точностью. Особенно важно стремится к этому в случае Демосфена, который так «многогранен и переменчив» (varius et multiplex), что кажется, будто его одушевлённая речь движется и живёт. Дурной же перевод, заросший «сорняками или добавленного, или убавленного, или изменённого, или переставленного слова» (aut addito aut detracto aut mutato vel transposito verbo... sordescat) умерщвляет эту речь и предаёт её земле.

Итак, несмотря на уже существующие переводы, великая речь Демосфена, по мнению Георгия, всё ещё недоступна латинянам. Он решил это исправить и «попытался во всём так ему на латинском языке подражать, чтобы сила и многообразие его, хотя не подлинное, но мнимое, по крайней мере, казалось бы если не переданным, то приближенным, если не изображённым, то слегка очерченным» (conatus sum in omnibus sic eum Latine imitari ut vis et varietas sua etsi non vera sed simulata, si non expressa sed tacta, si non picta sed adumbrata saltem esse videatur). При этом он подчёркивает, как трудна эта задача, сравнивая написание собственного сочинения со свободным произвольным движением, а перевод - с попытками подражать движению другого человека. Затем он снова возвращается к недостаткам предыдущих переводов и, по всей видимости, в первую очередь перевода Бруни: он упрекает своих современников в том, что при переводе они пропускают целые фрагменты как малополезные (quasi parum utilia) и становятся для авторов 
«не переводчиками, а цензорами и судьями» (non traductores, sed censores et iudices). Он пишет, что если бы Демосфен счёл пропущенные ими указы и документы ненужными, то и сам не включил бы их в речь. Именно поэтому Георгий в своём переводе стремится отразить не только смысл и убедительность аргументов оратора, но и «клаузулы, перечни и разделы» (clausulas, numeros, membraque). Таким образом, точность перевода оказывается для него не менее важной, чем красноречие, - и не только в случае философских и научных трактатов.

\section{$* * *$}

Разные подходы двух выдающихся гуманистов к переводу одного и того же произведения показывают, насколько сложной и противоречивой представлялась в эпоху Возрождения проблема перевода. Уже то, как настоятельно Георгий Трапезундский подчёркивает важность, казалось бы, вполне разумного принципа тщательного воспроизведения в переводе всех особенностей оригинала, показывает, что далеко не все его современники считали это необходимым требованием к хорошему переводу, а зачастую даже восставали против него, ратуя за свободу переводчика решать, что и как именно ему надлежит передать читателю. Совершенно неслучайно во множестве метафор, к которым в эпоху Возрождения прибегали для описания перевода, активной и даже совершающей некоторое насилие предстаёт фигура переводчика, который по праву победителя перекладывает «плененные мысли» на свой язык, «идёт по следам» автора оригинала, подобно горняку добывает драгоценные камни смысла, словно алхимик, переливает содержание из сосуда одного языка в другой, и даже пожирает и «переваривает» своего автора (то есть его мысли и стиль), будто каннибал (Hermans 1985: 113-126); в этом ряду более чем уместны судья и цензор Георгия Трапезундского. При этом не стоит забывать, что яростно отстаиваемые убеждения ренессансных гуманистов могли изменяться - как под давлением аргументов их коллег и соперников, так и в силу обстоятельств написания того или иного сочинения.

\section{Литература}

Авл Геллий 2007 - Авл Гелий. Аттические ночи / книги I-X / пер. А. Б. Егорова (кн. 1-5), А. П. Бехтер (кн. 6-10). Под общ. ред. А. Я. Тыжова, А. П. Бехтер. СПб, 2007.

Боэций 1990. - Боэций. Комментарий к Порфирию, им самим переведённому // Боэций. Утешение философией и другие трактаты. М.: Наука, 1990.

Гораций 1936 - Квинт Гораций Флакк. Полное собрание сочинений / под ред. Ф. А. Петровского. М.-Л.: Academia, 1936.

Иероним 2015 - Иероним Стридонский. К Паммахию о наилучшем способе пере- 
вода / пер. Н. Холмогоровой, под ред. М. Касьян и Т. Миллер // Иероним Стридонский. Сочинения. М.: Директ-Медия. С. 314-335.

Леонардо Бруни 2010 - Леонардо Бруни. О правильном переводе / пер. И. Ю. Шабага // Вестник Московского университета. Сер. 22. Теория перевода. 2010. № 1. С. 30-65.

Платон 1999 - Платон. Законы. Послезаконие / пер. А. Н. Егунова // Платон. Законы. М.: Мысль, 1999.

Цицерон 1901 - Цищерон. О наилучшем роде ораторов // Марк Туллий Цицерон. Полное собрание речей в русском переводе (отчасти В. А. Алексеева, отчасти Ф. Ф. Зелинского). Т. 1. СПб.: Изд. А. Я. Либерман, 1901.

Цицерон 1975 - Цицерон. Тускуланские беседы / перевод с латинского и комментарии М. Л. Гаспарова // Марк Туллий Цицерон. Избранные сочинения. М.: «Художественная литература», 1975.

Шабага 2010 - Шабага И. Ю. Трактат Леонардо Бруни «О правильном переводе»// Вестник Московского университета. Сер. 22. Теория перевода. 2010. № 1. C. 27-30.

Castellani 1896 - Castellani G. Giorgio da Trebisonda: maestro di eloquenza a Vicenza e a Venezia // Nuovo Arch. Veneto, XI. 1896. P. 123-142.

Copeland 1991 - Copeland Rita. Rhetoric, Hermeneutics, and Translation in the Middle Ages: Academic Traditions and Vernacular Texts (Cambridge Studies in Medieval Literature). Cambridge: Cambridge University Press, 1991.

Davies 1988 - Davies M. C. Leonardo Bruni and Demosthenes // The Classical Review, New Series. 1988. Vol. 38, no. 1. P. 131-134.

Flashar 1968 - Flashar H. Formen der Aneignung griechischer Literatur durch die Übersetzung // Arcadia. 1968. Bd. 3. S. 133-156.

Mohler 1942 - Mohler L. Kardinal Bessarion als Theologe, Humanist und Staatsmann: Funde und Forschungen. Bd. III. Paderborn: Ferdinand Schoningh, 1942. S. 275-344.

Hankins 2014 - Hankins J. Leonardo Bruni // Western translation theory: from Herodotus to Nietzsche / ed. by Douglas Robinson. London: Routledge, 2014. P. 57-60.

Hankins 1990 - Hankins J. Plato in the Italian Renaissance. Vol. 1. NY: Brill, 1990.

Hermans 1985 - Hermans Th. Images of translation. Metaphor and Imagery in the Renaissance Discourse on Translation // The Manipulation of Literature. Studies in Literary Translation / ed. by Theo Hermans. London \& Sydney: Croom Helm, 1985. P. 103-135.

Kelly 2009 - Kelly L. G. Latin tradition // Routledge Encyclopedia of Translation Studies / ed. by Mona Baker, Gabriela Saldanha. London: Routledge, 2009.

Linde 2018 - Linde J. C. Translating Aristotle in Fifteenth-Century Italy: George of Trebizond and Leonardo Bruni // Et Amicorum: Essays on Renaissance Humanism and Philosophy, in Honour of Jill Kraye / ed. by Anthony Ossa-Richardson and Margaret Meserve. (Brill's Studies in Intellectual History 273). Leiden: Brill, 2018. P. 47-68.

Monfasani 2006 - Monfasani J. George of Trebizond's Critique of Theodore Gaza's Translation of the Aristotelian Problemata // Aristotle's Problemata in Different 
Times and Tongues / ed. by Pieter De Leemans, Michéle Goyens. Leuven: Leuven University Press, 2006. P. 275-294.

Monfasani 1976 - Monfasani J. George of Trebizond: A Biography and a Study of His Rhetoric and Logic. Leiden: Brill, 1976.

Monfasani 1983 - Monfasani J. (ed.) Collectanea Trapezuntiana: Texts, Documents, and Bibliographies of George of Trebizond. Binghamton, N.Y.: Medieval \& Renaissance Texts \& Studies, 1983.

Monfasani 2018 - Monfasani J. George of Trebizond, Thomas Aquinas, and Latin Scholasticism // Never the Twain Shall Meet? Latins and Greeks learning from each other in Byzantium / ed. by Denis Searby. Berlin-Boston: Walter de Gruyter, 2018. P. 47-61.

Viti 2001 - Viti P. Giorgio da Trebisonda // Dizionario Biografico degli Italiani. Roma, 2001. Vol. 55. P. 373-382.

Zaharia 2014 - Zaharia O.-A. "De interpretatione recta...": Early Modern Theories of Translation // American, British and Canadian Studies. 2014. Vol. 23, no. 1. P. 5-24. 